\title{
PIWI-interacting RNAs as novel regulators of pancreatic beta cell function
}

\author{
Imène Sarah Henaoui ${ }^{1}$ - Cécile Jacovetti ${ }^{1}$ Inês Guerra Mollet ${ }^{2}$ - Claudiane Guay ${ }^{1}$. \\ Jonathan Sobel ${ }^{1} \cdot$ Lena Eliasson $^{2} \cdot$ Romano Regazzi $^{1}$ (I)
}

Received: 20 January 2017 / Accepted: 1 June 2017 / Published online: 16 July 2017

(C) Springer-Verlag GmbH Germany 2017

\begin{abstract}
Aims/hypothesis P-element induced Wimpy testis (PIWI)interacting RNAs (piRNAs) are small non-coding RNAs that interact with PIWI proteins and guide them to silence transposable elements. They are abundantly expressed in germline cells and play key roles in spermatogenesis. There is mounting evidence that piRNAs are also present in somatic cells, where they may accomplish additional regulatory tasks. The aim of this study was to identify the piRNAs expressed in pancreatic islets and to determine whether they are involved in the control of beta cell activities.

Methods piRNA profiling of rat pancreatic islets was performed by microarray analysis. The functions of piRNAs were investigated by silencing the two main Piwi genes or by modulating the level of selected piRNAs in islet cells.

Results We detected about 18,000 piRNAs in rat pancreatic islets, many of which were differentially expressed throughout islet postnatal development. Moreover, we identified changes in the level of several piRNAs in the islets of Goto-Kakizaki rats, a well-established animal model of type 2 diabetes. Silencing of Piwil2 or Piwil4 genes in adult rat islets caused a reduction in the level of several piRNAs and resulted in defective insulin secretion and increased resistance of the cells
\end{abstract}

Electronic supplementary material The online version of this article (doi:10.1007/s00125-017-4368-2) contains peer-reviewed but unedited supplementary material, which is available to authorised users.

Romano Regazzi

Romano.Regazzi@unil.ch

1 Department of Fundamental Neurosciences, University of Lausanne, Rue du Bugnon 9, CH-1005 Lausanne, Switzerland

2 Department of Clinical Sciences-Malmö, Lund University Diabetes Centre, Lund University, Clinical Research Centre, SUS,

Malmö, Sweden to cytokine-induced cell death. Furthermore, overexpression in the islets of control animals of two piRNAs that are upregulated in diabetic rats led to a selective defect in glucoseinduced insulin release.

Conclusions/interpretation Our results provide evidence for a role of PIWI proteins and their associated piRNAs in the control of beta cell functions, and suggest a possible involvement in the development of type 2 diabetes.

Data availability Data have been deposited in Gene Expression Omnibus repository under the accession number GSE93792. Data can be accessed via the following link: https://www.ncbi.nlm.nih.gov/geo/query/acc.cgi?token= ojklueugdzehpkv\&acc=GSE93792

Keywords Diabetes · Insulin secretion · Pancreatic islets · piRNAs $\cdot$ Piwil genes
Abbreviations
GK Goto-Kakizaki
piRNA PIWI-interacting RNA
PIWI P-element induced Wimpy testis
qRT-PCR Quantitative reverse transcription real-time PCR siRNA Small interfering RNA

\section{Introduction}

P-element induced Wimpy testis (PIWI)-interacting RNAs (piRNAs) are small non-coding RNAs that are very abundant in animal gonads. They were named from their ability to associate with Argonaute proteins of the PIWI subfamily [1-4]. piRNAs share common biochemical features, including the phosphorylation of the $5^{\prime}$ end and the 2-O-methylation of the $3^{\prime}$ end. Mature piRNAs are processed via a maturation pathway 
involving the cleavage by PIWI proteins of long singlestranded RNAs transcribed from 'piRNA clusters' present in both intra- and intergenic regions of the genome $[5,6]$.

piRNAs are believed to maintain genome integrity by guiding PIWI proteins to repress transposon activity, regulate the assembly of the telomere protection complex and be involved in RNA silencing and in the epigenetic control of gene expression [5, 7-9]. Until recently, the piRNA pathway was perceived as germline-specific, but piRNAs have also been detected in stem cells and other cell types, suggesting that these small noncoding RNAs may accomplish additional tasks [10-12]. Despite the poorly understood role of piRNAs in somatic cells, there is increasing evidence indicating that these non-coding RNAs control gene expression by acting at genomic and also at transcriptional and post-transcriptional levels [13-17]. Indeed, recent studies have highlighted the involvement of the PIWI-piRNA pathway in both physiological and pathological processes, including development [18], memory [19], liver regeneration [20] and cancer [21-26]. However, nothing is known about their role in metabolic diseases, such as diabetes.

Pancreatic islets play key roles in the regulation of metabolism and energy homeostasis by secreting hormones in response to changes in nutritional status. Pancreatic beta cell dysfunction and loss are critical determinants for the development of type 2 diabetes. There is strong evidence indicating that altered expression of both protein-coding and non-coding genes is associated with beta cell dysfunction under conditions of impaired glucose tolerance and diabetes [27]. Several studies have implicated miRNAs and long noncoding RNAs as key players in diabetes [28-30]. So far, no information has been available about the presence of PIWIpiRNAs complexes in beta cells and their possible involvement in islet physiology and the development of diabetes. The goal of this study was to analyse the piRNA expression patterns of rat pancreatic islets under both physiological and pathological conditions, and to assess their contribution to the maintenance of beta cell function.

\section{Methods}

\section{Animals}

Male Sprague Dawley and Wistar rats and pregnant female Sprague Dawley rats were obtained from Janvier Laboratories (Le Genest-Saint-Isle, France) and housed under a $12 \mathrm{~h}$ light, $12 \mathrm{~h}$ dark cycle in climate-controlled and pathogen-free facilities. The detailed sources of Goto-Kakizaki (GK) rats have previously been described [31]. All animal procedures were performed in accordance with the National Institutes of Health guidelines and were approved by the Swiss Research Councils and Veterinary Offices or by the local ethics committee in Malmö.
Islet isolation, organ collection and cell culture Rat pancreatic islets were isolated by collagenase digestion (Roche Diagnostics, Rotkreuz Switzerland), followed by purification on a Histopaque density gradient (Sigma-Aldrich, St Louis, MO, USA) [32] and final cleaning by hand-picking. The islets were cultured in RPMI 1640 Glutamax medium (Invitrogen, Carlsbad, CA, USA), supplemented with $10 \%$ FCS (Gibco, Zug Switzerland), $100 \mu \mathrm{g} / \mathrm{ml}$ streptomycin, $100 \mathrm{IU} / \mathrm{ml}$ penicillin, $1 \mathrm{mmol} / 1$ sodium pyruvate and $10 \mathrm{mmol} / \mathrm{l}$ HEPES, $\mathrm{pH}$ 7.4. Human islets obtained from the Cell Isolation and Transplantation Center (University of Geneva, Geneva, Switzerland) were cultured in CMRL1066 medium (Invitrogen) supplemented with $10 \% \mathrm{FCS}, 100 \mu \mathrm{g} / \mathrm{ml}$ streptomycin, $100 \mathrm{IU} / \mathrm{ml}$ penicillin, $2 \mathrm{mmol} / \mathrm{l} \mathrm{L}$-glutamine and $250 \mu \mathrm{mol} / 1$ HEPES. The use of human islets was approved by the Geneva local ethical committee. Dissociated islet cells were obtained by digestion with $5 \mathrm{mg} / \mathrm{ml}$ of trypsin (Gibco). Adipose tissue, brain, liver and skeletal muscle were collected from Wistar rats aged 12 weeks.

Fluorescence activated cell sorting of islet cells Dissociated islet cells from newborn and adult rats were sorted by FACS based on beta cell autofluorescence [33]. Immunocytochemistry analysis using anti-insulin antibodies (no. A0564, Dako, Basel, Switzerland) revealed that $94 \pm 1 \%$ of the cells in the purified fraction were insulin-positive.

Cell transfection Dissociated islet cells were transfected with predesigned small interfering RNAs (siRNAs; Life Technologies, Basel Switzerland), using as control an siRNA directed against GFP (Eurogentec, Seraing, Belgium). Synthetic RNA oligonucleotides with 5' phosphorylation and 3' 2-O-methylation (Integrated DNA Technologies, Leuwen Belgium) were used as piRNA mimics. Transfection was carried out using Lipofectamine RNAiMax (Invitrogen). To overexpress the piRNAs, we used the following sequences: (DQ732700) 5'-UAUGAAGA AUGACUUGGGGUACAUGACC-3'; (DQ746748) 5'ACUGGAAACGGAAAACUCAGAGCGCCC-3'; control oligonucleotide 5'-GUGUAACACGUCUAUACGCCCA-3'. Functional assays were performed $48 \mathrm{~h}$ after transfection.

Insulin secretion Islet cells were preincubated in Krebs buffer containing $25 \mathrm{mmol} / \mathrm{l}$ HEPES, pH 7.4, 0.1\% BSA (SigmaAldrich) and $2 \mathrm{mmol} / \mathrm{l}$ glucose for $30 \mathrm{~min}$ at $37^{\circ} \mathrm{C}$. The medium was then replaced by Krebs buffer containing $0.1 \%$ BSA supplemented with $2 \mathrm{mmol} / \mathrm{l}$ glucose, $20 \mathrm{mmol} / 1$ glucose or $2 \mathrm{mmol} / \mathrm{l}$ glucose and $35 \mathrm{mmol} / \mathrm{l} \mathrm{KCl}$. After $45 \mathrm{~min}$, the supernatant fractions were collected and centrifuged at $1200 \mathrm{~g}$ for $5 \mathrm{~min}$ to remove cell debris. Total cellular insulin contents were recovered in $\mathrm{EtOH}$ acid $(75 \%$ ethanol, $0.55 \% \mathrm{HCl})$, and protein contents were collected on ice in a lysis buffer containing $50 \mathrm{mmol} / \mathrm{l}$ Tris-HCl, pH 7.5, $5 \mathrm{mmol} / \mathrm{l}$ EDTA, 0.5\% 
Triton X-100 and protease inhibitors (Roche). The amount of insulin in the samples was determined by ELISA (Mercodia, Uppsala, Sweden). Protein content was evaluated using the Bradford protein assay (Bio-Rad, Reinach, Switzerland).

Proliferation assay Dissociated islet cells were cultured on poly-L-lysine-coated glass coverslips and treated, or not, for $48 \mathrm{~h}$ with $500 \mathrm{ng} / \mathrm{ml}$ prolactin (Sigma-Aldrich) to stimulate proliferation. The cells were fixed in $4 \%$ paraformaldehyde and incubated with PBS supplemented with $0.5 \%$ saponin (Sigma-Aldrich) for $20 \mathrm{~min}$. The coverslips were incubated for $30 \mathrm{~min}$ in PBS supplemented with $0.5 \%$ saponin and $1 \%$ BSA and exposed for $1 \mathrm{~h}$ to the following antibodies: 1:1500 rabbit anti-Ki67 (Abcam, Cambridge, UK) and 1:100 guinea pig anti-insulin (Millipore, Zug, Switzerland). They were then washed and incubated for $1 \mathrm{~h}$ with goat anti-rabbit Alexa Fluor 488 or goat anti-guinea pig Alexa Fluor 594 diluted at 1:400 (Invitrogen). Finally, the coverslips were incubated for 10 min with Hoechst 33342 (Invitrogen) and mounted on microscope glass slides. The cells were visualised with a Zeiss AxioVision fluorescence microscope (Zeiss, Feldbach, Switzerland). At least 600 cells were analysed for each condition. The total number of cells was assessed using ImageJ software (https://imagej.net/), while Ki67-positive cells were counted manually.

Cell death assessment Cell death was triggered by exposing the cells to proinflammatory cytokines $(30 \mathrm{ng} / \mathrm{ml} \mathrm{IFN}-\gamma$, $10 \mathrm{ng} / \mathrm{ml} \mathrm{TNF}-\alpha$ and $0.1 \mathrm{ng} / \mathrm{ml} \mathrm{IL-1} \beta$ ) for $24 \mathrm{~h}$. The cells were incubated for $5 \mathrm{~min}$ at $37^{\circ} \mathrm{C}$ with Hoechst 33342 (Invitrogen). About 400 cells per condition were analysed by fluorescence microscopy (Axio Vert 25; Zeiss) to score the fraction displaying pyknotic nuclei.

RNA extraction and measurement Total RNA from islets or from other rat organs was extracted using the miRNeasy kit (Qiagen, Basel, Switzerland). For microarray analysis and quantitative reverse transcription real-time PCR (qRT-PCR), pancreatic islets from two to five 10-day-old pups (without sex distinction) were pooled, while islets from adult male rats were extracted individually. piRNA levels were measured using specific custom primers and the miScript Plant RT kit (Qiagen). Measurement of mRNA levels was performed by qRT-PCR (SsoAdvanced Universal SYBR Green Supermix; Bio-Rad) using custom primers (Microsynth, Balgach, Switzerland) (see electronic supplementary material [ESM] Methods). All PCR products were validated by sequencing (Microsynth). piRNA expression was normalised to U6, while mRNA expression was normalised to $\alpha$-tubulin mRNA using the $\Delta \mathrm{C}_{\mathrm{t}}$ method.

piRNA profiling Global piRNA profiling was carried out using a Rat piRNA Array (Arraystar, Rockville, MD, USA).
Rat piRNA sequences from the NCBI database were mapped to the RN4 genome using UCSC Blat (https://genome.ucsc. edu). Probes for about 40,000 piRNAs were spotted on an Agilent array platform (Agilent Technologies, Santa Clara, CA, USA). Samples were labelled using a RNA ligase method and hybridised onto the piRNA Array in Agilent's SureHyb Hybridization Chambers. Quantile normalisation and data processing were performed using the GeneSpring GX v11.5.1 software (Agilent Technologies). Differentially expressed piRNAs with statistical significance between the two groups were identified through volcano plot filtering. Hierarchical clustering was performed to show the distinguishable piRNA expression pattern among samples.

Prediction of piRNA target genes The putative binding sites of DQ732700 and DQ746748 present in the 3' UTR sequences of all the genes expressed in rat islets [34] were identified with the Probability of Interaction by Target Accessibility (PITA) algorithm using default parameters [35]. For each piRNA, the top 300 putative targets based on the PITA score were annotated with their gene ontology using biomaRt (http://www.ensembl.org/info/data/biomart/ biomart_r_package.html) [36]. Pathway enrichment analysis was performed using DAVID (https://david.ncifcrf.gov/) with Kyoto Encyclopedia of Genes and Genomes (KEGG) and Reactome pathway annotations.

Statistical analysis Statistical differences were tested using Student's $t$ test or, for multiple comparisons, one-way ANOVA followed by a post hoc Dunnett's test, with a discriminating $p$ value of 0.05 (GraphPad Software, San Diego, CA). Differences in piRNAs expression between purified beta cells of 10-day-old and adult rats were assessed using 1sample $t$ test, with a discriminating $p$ value of 0.05 using the Statistical Package for the Social Sciences (IBM SPSS version 23, www.ibm.com/analytics/us/en/technology/spss/).

\section{Results}

The PIWI/piRNA pathway is active in rat pancreatic islets There is mounting evidence to suggest that, in addition to their well-established role in germinal cells, piRNAs may also contribute to the regulation of somatic cell activities [11]. To investigate the potential involvement of piRNAs in the control of pancreatic beta cell functions, we first assessed whether insulin-secreting cells expressed some of the key components of the piRNA pathway. Although to a much lower level compared with rat testis (Fig. 1a), qRT-PCR analysis revealed the expression in rat pancreatic islets of the PIWI-like genes Piwil2 and Piwil4 but not Piwill (Fig. 1b). The expression of these two PIWI-like genes was confirmed in FACS-sorted beta cells from adult (3-month-old) (Fig. 1c) and newborn 
Fig. 1 Pancreatic islets express several components of the Piwil-piRNA pathway. qRT-PCR measurement of the level of Piwil mRNA in rat testis (a), rat pancreatic islets (b), FACS-sorted rat beta cells (c) and human islets (d). qRT-PCR analysis of the mRNAs of selected components of the Piwil-piRNA pathway in rat testis (e) and rat islets (f). Data are mean $\pm \mathrm{SD}, n=3-4$. ND, not detected
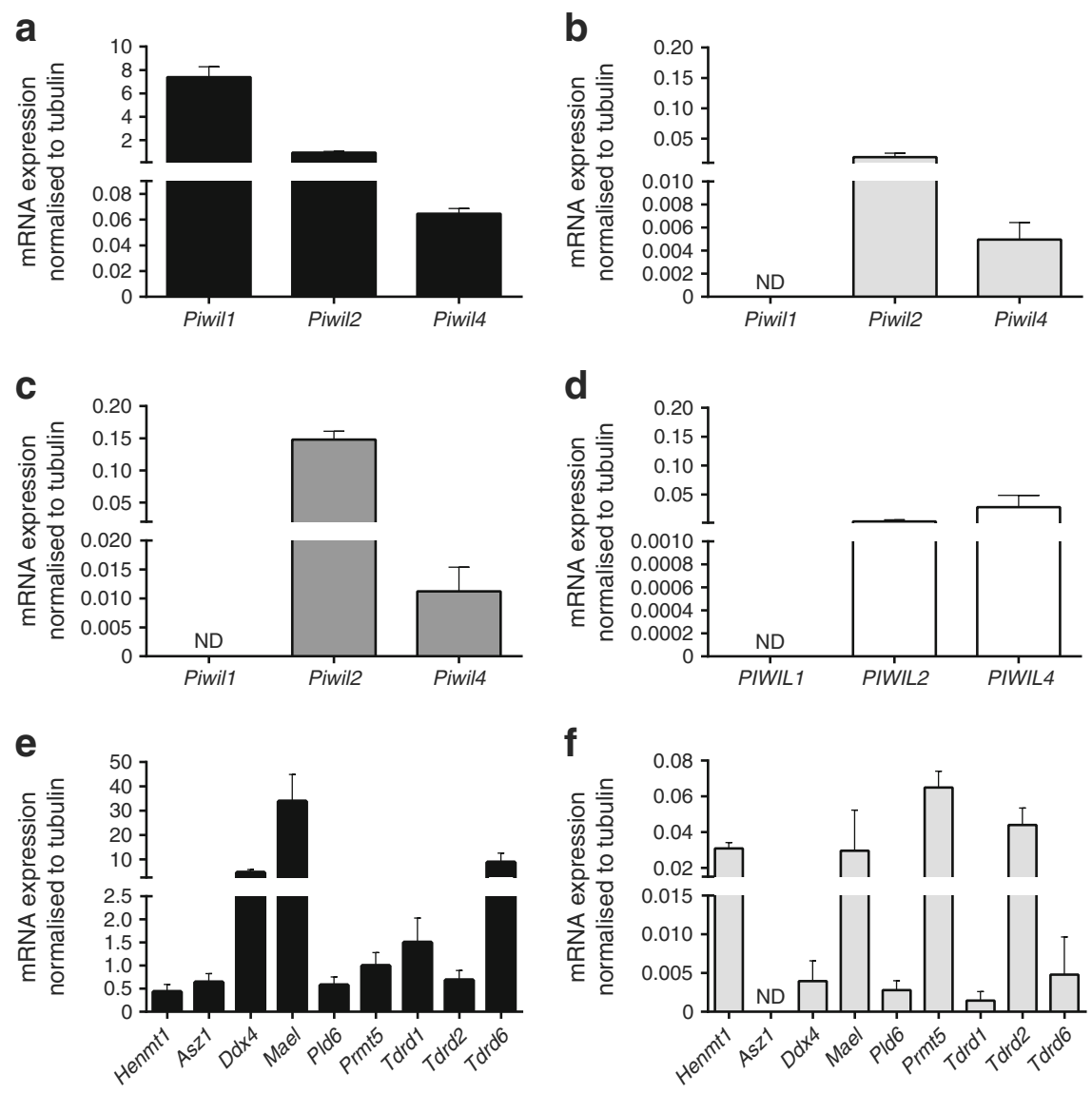

(10-day-old) rats (ESM Fig. 1). Similar findings were obtained with human pancreatic islets that were found to express the human orthologues of these genes, PIWIL2 (also known as HILI) and PIWIL4 (also known as HIWI2) (Fig. 1d). The expression of PIWI-like genes in islets was comparable with the level measured in other somatic tissues such as adipose tissue, brain, liver and skeletal muscle (ESM Fig. 1). Beside Piwil2 and Piwil4, qRT-PCR analysis also unveiled the presence in rat pancreatic islets of the mRNAs of several other genes involved in piRNA biogenesis [5, 6, 37], including Henmt 1, Mael, Ddx4, Pld6 and Prmt5, which are main players in the pathway, as well as some of the Tudor domaincontaining genes [38], Tdrd1, Tdrd2 (also known as Tdrkh) and $\operatorname{Tdrd} 6$ (Fig. 1e, f).

The presence of several components of the piRNA pathway prompted us to assess whether pancreatic islets expressed a specific pool of piRNAs. Indeed, analysis of islet RNA isolated from adult and newborn rats using a dedicated microarray allowed the detection of 18,540 of the 40,000 tested piRNAs (GSE93790). Hierarchical clustering summarises the most differentially regulated piRNAs (Fig. 2a).

We then assessed whether islet piRNA expression would be modulated in response to physiological or pathological conditions. Newborn beta cells display major functional differences compared with fully mature beta cells. Neonatal beta cells show a much higher proliferation rate than adult beta cells [34]. Moreover, newborn beta cells are unable to secrete insulin in response to glucose, acquiring this property only after undergoing a postnatal maturation process that involves a major rearrangement in the gene expression profile [34]. We observed that the functional maturation of beta cells was associated with changes in the level of numerous piRNAs. Indeed, by comparing the levels in newborn (10-day-old) and adult (3-month-old) rat islets by microarray analysis, we found that the expression of 735 piRNAs was reduced, whereas that of 1056 piRNAs was increased upon functional beta cell maturation (nominal $p \leq 0.05$, fold change $\geq 2$ ) (GSE93790). The observed changes in the level of selected piRNAs were confirmed by qRT-PCR in whole islets (Fig. 2b) and in highly purified beta cell fractions (Fig. 2c). These findings suggest that piRNAs may possibly contribute to the functional maturation of beta cells.

We next assessed whether altered piRNA expression could contribute to the beta cell dysfunction observed under diabetic conditions. For this purpose, we compared the piRNA expression profile of the islets of Wistar and GK rats, a wellestablished animal model of non-obese type 2 diabetes characterised by impaired glucose-stimulated insulin secretion [31, 39]. By microarray analysis, we identified 347 piRNAs that were differentially expressed $(p \leq 0.05$, fold change $\geq 2)$ in 
Fig. 2 Changes in the level of piRNAs during beta cell maturation. (a) Hierarchical clustering of 236 piRNAs that were differentially regulated $(p<0.05$, absolute fold change $>2$, normalised expression $>6$ ) between pancreatic islets of adult and newborn rats. piRNAs displaying an upregulation compared with the other group are in yellow, and those displaying a downregulation are in blue. Dark shading represents no significant change. The level of the indicated piRNAs in whole islets (b) and purified beta cells (c) of newborn (black bars) and adult rats (white bars) was analysed by qRT-PCR. Data are mean \pm SD of the $\Delta C_{t}$ values. Statistical differences were assessed by Student's $t$ test: ${ }^{*} p \leq 0.05, * * p \leq 0.01, n=3$

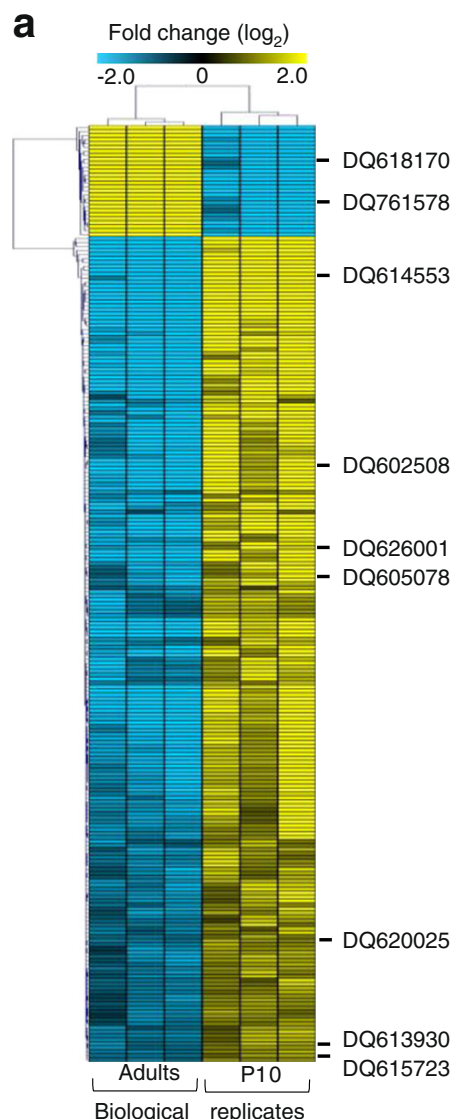

the islets of diabetic GK rats (128 upregulated and 219 downregulated) (GSE93791). Hierarchical clustering summarises the most differentially regulated piRNAs (Fig. 3a). The changes in the level of three of these piRNAs was confirmed by qRT-PCR (Fig. 3b). Thus, our results indicate that the piRNA expression profile is modified under diabetic conditions, potentially contributing to the development of the disease.

PIWI/piRNAs impact on beta cell functions We next investigated whether global changes in piRNA activity would impact on beta cell functions. For this purpose, we used RNA

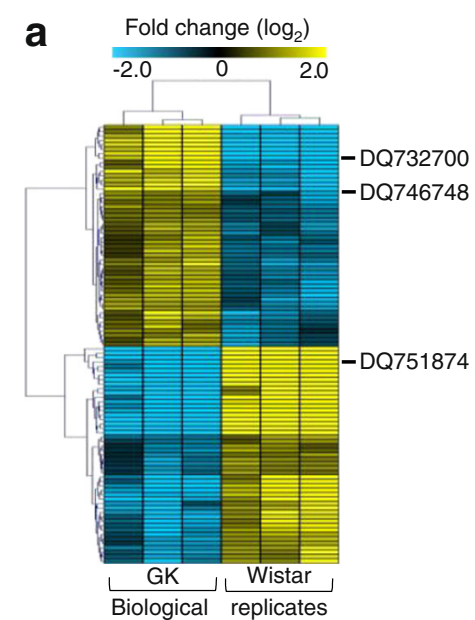

Fig. 3 Changes in piRNA expression in rat models of type 2 diabetes. (a) Hierarchical clustering of 99 piRNAs $(p<0.05$, absolute fold change $>2$, normalised expression $>6$ ) differentially expressed between GK and Wistar rat islets. Dark shading represents no significant change, yellow an upregulation and blue a downregulation. (b) The expression of the b

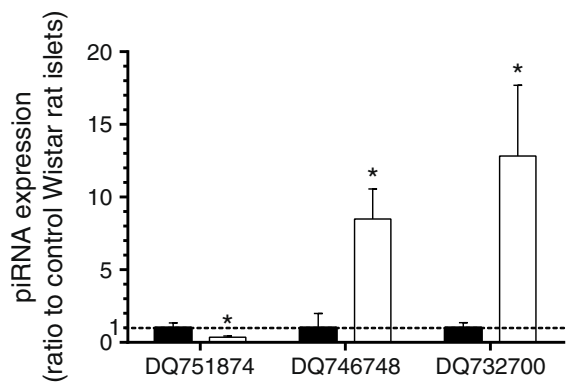

three indicated piRNAs in the islets of GK (white bars) and Wistar rats (black bars) was measured by qRT-PCR. Data are mean \pm SD of the $\Delta \mathrm{C}_{t}$ values. Statistical differences were assessed by Student's $t$ test: * $p \leq 0.05$, $n=3$ 
interference to silence the Piwil2 and Piwil4 genes in pancreatic islet cells. siPiwil2 and siPiwil4 reduced the expression of their target mRNAs by about $80 \%$ and $50 \%$, respectively (Fig. 4a,b). Silencing of Piwil2 and Piwil4 genes resulted in a reduction in the level of several piRNAs (Fig. 4c). To investigate whether the impaired piRNA expression would affect the activities of beta cells, we measured insulin secretion in response to glucose or to depolarising $\mathrm{KCl}$ concentrations upon silencing of Piwil2 or Piwil4 in islet cells. We found that knockdown of Piwil2 or Piwil4 did not affect insulin content (Fig. 5a, c). However, in the absence of Piwil2 or Piwil4, both glucose- and KCl-induced insulin secretion were significantly decreased (Fig. 5b, d), suggesting a functional impairment in the secretory machinery that could also involve a defect in glucose metabolism. We then tested cell survival and proliferation. This revealed that, upon silencing of Piwil2 or Piwil4, beta cells became more resistant to cytokine-induced cell death (Fig. 5e). In contrast, beta cell proliferation both in the presence or absence of the mitogenic hormone prolactin was not significantly affected (Fig. 5f).

The observed changes in expression of piRNAs occurring during the acquisition of the mature beta cell phenotype and in diabetic conditions suggest that deregulation of specific piRNAs may potentially contribute to beta cell dysfunction in disease states. To test this hypothesis, we overexpressed DQ732700 and DQ746748 piRNAs in the islet cells of normoglycaemic Wistar rats, in order to mimic the increase

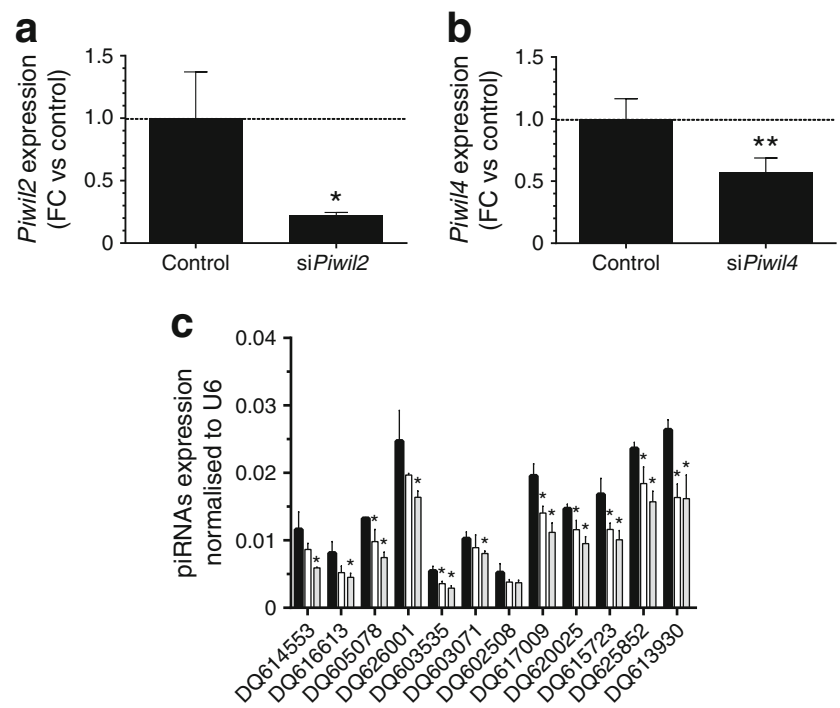

Fig. 4 Downregulation of Piwil2 and Piwil4 expression in rat islet cells using siRNAs. (a-c) Expression of the indicated mRNAs and piRNAs was measured by qRT-PCR. (a, b) Dissociated rat islet cells were transfected with a control siRNA or with siRNAs directed against Piwil2 (a) or Piwil4 (b). The expression of the indicated mRNAs was measured $48 \mathrm{~h}$ after transfection by qRT-PCR (FC, fold change vs control siRNA). (c) The level of the indicated piRNAs was measured by qRTPCR $48 \mathrm{~h}$ after transfection with a control siRNA (black bars), siPiwil2 (white bars) or siPiwil4 (grey bars). Data are mean \pm SD. Statistical differences were assessed by Student's $t$ test vs control: $* p \leq 0.05$, $* * p \leq 0.01, n=3-5$ observed in the islets of diabetic GK rats, and assessed the impact on insulin secretion. We found that overexpression of DQ732700 or DQ746748 did not affect cellular insulin content (Fig. 6a, c). However, the increase in the level of these two piRNAs resulted in a decrease in insulin release in the presence of elevated glucose concentrations (Fig. 6b). In contrast, insulin secretion in response to depolarising concentrations of $\mathrm{KCl}$ was not affected (Fig. 6d). As type 2 diabetes is in some cases associated with beta cell apoptosis, we also assessed whether the overexpression of these two piRNAs would affect the survival of the insulin-secreting cells. As shown in Fig. 6e, the increase in these two piRNAs did not modify the survival of the cells in either the presence or absence of a mix of proinflammatory cytokines including IL- $1 \beta$, TNF- $\alpha$ and IFN- $\gamma$.

piRNAs have been proposed to exert a translational repression through mechanisms similar to those of miRNAs [14]. Thus, we used a computational approach to search for the potential targets of DQ732700 and DQ746748. Interestingly, the putative targets of these piRNAs were significantly enriched for genes involved in insulin secretion and insulin action (GSE93792; ESM Tables 1 and 2).

\section{Discussion}

Type 2 diabetes is characterised by a diminished sensitivity of insulin target tissues and defective insulin secretion from beta cells. The mechanisms underlying these phenomena are not fully understood but appear to involve alterations in the expression of mRNAs and non-coding RNAs [28-30]. piRNAs constitute an abundant class of non-coding RNAs and contribute to genome stability. In germ cells, they interact with PIWI proteins during early embryogenesis, enabling the silencing of transposable elements in the genome [5]. In addition to their well-established role in the germline, there is emerging evidence for an involvement of these small RNAs in the regulation of gene expression in somatic cells [10-12, 40]. However, the presence of piRNAs in beta cells and their possible contribution to the regulation of gene expression have so far not been explored. In this study, we used a microarray approach to obtain a comprehensive picture of the piRNAs expressed in rat pancreatic islets and to evaluate the modifications taking place during the acquisition of a fully mature beta cell phenotype. This led to the identification of a large number of piRNAs, many of which display changes in their level occurring in association with the functional maturation of beta cells. These findings suggest that piRNAs may potentially contribute to the development of pancreatic beta cells. Additional studies will be needed to delineate the precise role of piRNAs in the acquisition of specific properties of beta cells, such as the capacity to secrete insulin in response to glucose.

PIWI proteins are essential for the biogenesis and activity of piRNAs and have been suggested to be involved in the 

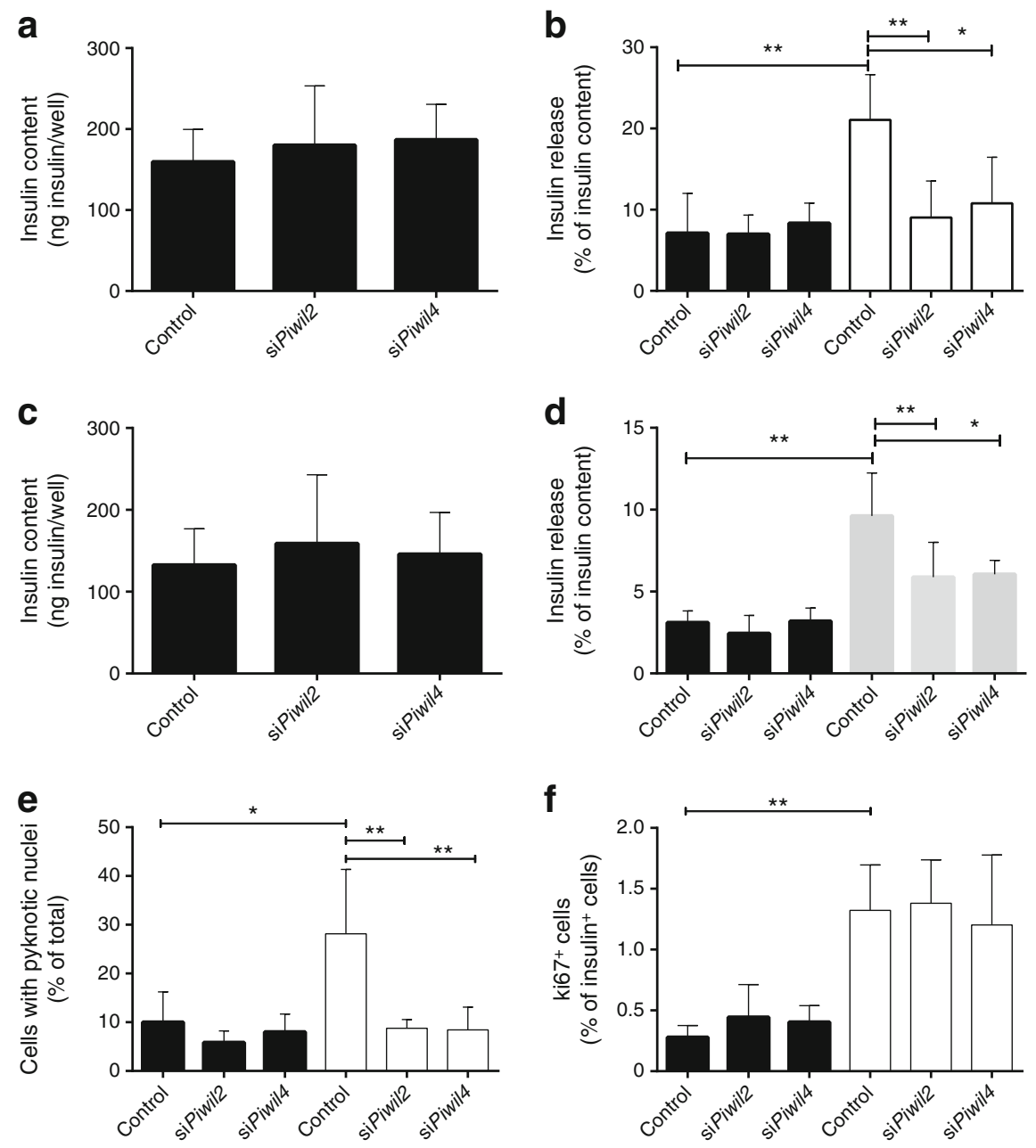

Fig. 5 Functional impact of Piwil2 and Piwil4 silencing. Dissociated rat islet cells were transfected with a control siRNA or with siRNAs directed against Piwil2 or Piwil4. The secretory properties of the cells were assessed $48 \mathrm{~h}$ later. (a) Insulin content and (b) insulin secretion in the presence of $2 \mathrm{mmol} / \mathrm{l}$ (black bars) or $20 \mathrm{mmol} / \mathrm{l}$ glucose (white bars) were measured by ELISA. (c) Insulin content and (d) insulin secretion at $2 \mathrm{mmol} / \mathrm{l}$ glucose in the absence (black bars) or presence (grey bars) of $35 \mathrm{mmol} / 1 \mathrm{KCl}$. (e) Adult rat islet cells were transfected with the indicated siRNAs. One day later, the cells were incubated in the presence (white

bars) or absence (black bars) of proinflammatory cytokines (IL-1 $\beta$, TNF$\alpha$ and IFN- $\gamma$ ). Cell death was assessed $24 \mathrm{~h}$ later by counting the number of cells displaying pyknotic nuclei. (f) Proliferation of beta cells transfected with the indicated siRNAs was assessed by counting the fraction of cells positive for insulin and Ki67 in the presence (white bars) or absence (black bars) of $500 \mathrm{ng} / \mathrm{ml}$ prolactin. Data are mean \pm SD. Statistical differences were assessed by one-way ANOVA: $* p \leq 0.05$, $* * p \leq 0.01, n=4-5$

transcriptional, post-transcriptional and epigenetic regulation of gene expression [13-17, 40, 41]. We found that rat and human pancreatic islet cells express two PIWI genes. These observations were confirmed in highly purified beta cell fractions, rendering unlikely the possibility that the expression of these genes is confined exclusively to other cells present in the islets. Interestingly, downregulation of Piwil2 and Piwil4 mRNAs in rat islets resulted in a significant decrease in insulin secretion upon glucose or $\mathrm{KCl}$ stimulation, suggesting that the activity of these PIWI proteins is important to preserve the secretory capacity of beta cells. The silencing of Piwil2 and Piwil4 was associated with a decrease in the level of several piRNAs, suggesting that the effect may be linked to changes in the biogenesis, stability and/or activity of these small non-coding RNAs.

The involvement of piRNAs in pathological processes is starting to become clearer. Indeed, the levels of some of these small RNAs have been associated with different clinical conditions and have been proposed as prognostic markers for different types of cancer [42]. However, the understanding of the contribution of these non-coding RNAs to diseases is still rudimentary and necessitates further exploration. Piwil mRNA levels have been reported to be deregulated in cancerous tissues and to be correlated with clinicopathological features of the tumours [43-45]. In certain human cancers, Piwil2 has been reported to affect the survival of the cells by interacting with signal transducer and activator of transcription 3 (STAT3) and by regulating the p53 signalling pathway [46]. Moreover, Piwil4 has been shown to promote cell 
Fig. 6 Effect of the

overexpression of DQ732700 and rat islet cells were transfected with a control oligonucleotide or with oligonucleotides mimicking the sequence of DQ732700 or DQ746748 piRNAs. Two days later, the cells were incubated for $45 \mathrm{~min}$ with $2 \mathrm{mmol} / \mathrm{l}$ glucose, $20 \mathrm{mmol} / \mathrm{l}$ glucose or $35 \mathrm{mmol} / 1$ $\mathrm{KCl}$. (a) Insulin content and (b) insulin secretion at $2 \mathrm{mmol} / \mathrm{l}$ (black bars) and $20 \mathrm{mmol} / 1$ (white bars) glucose. (c) Insulin content and (d) insulin secretion at $2 \mathrm{mmol} / \mathrm{l}$ glucose in the absence (black bars) or presence (grey bars) of $35 \mathrm{mmol} / 1 \mathrm{KCl}$. (e) Rat islet cells were transfected with following day, the cells were incubated in the absence (black bars) or presence (white bars) of IL- $1 \beta$, TNF- $\alpha$ and IFN- $\gamma$. Cell death was assessed $24 \mathrm{~h}$ later by counting the number of cells displaying pyknotic nuclei. Data are mean \pm SD. Statistical differences were assessed by oneway ANOVA: $* p \leq 0.05$,

$* * p \leq 0.01, n=5-6$ DQ746748 piRNAs. Dissociated the indicated piRNAs. The
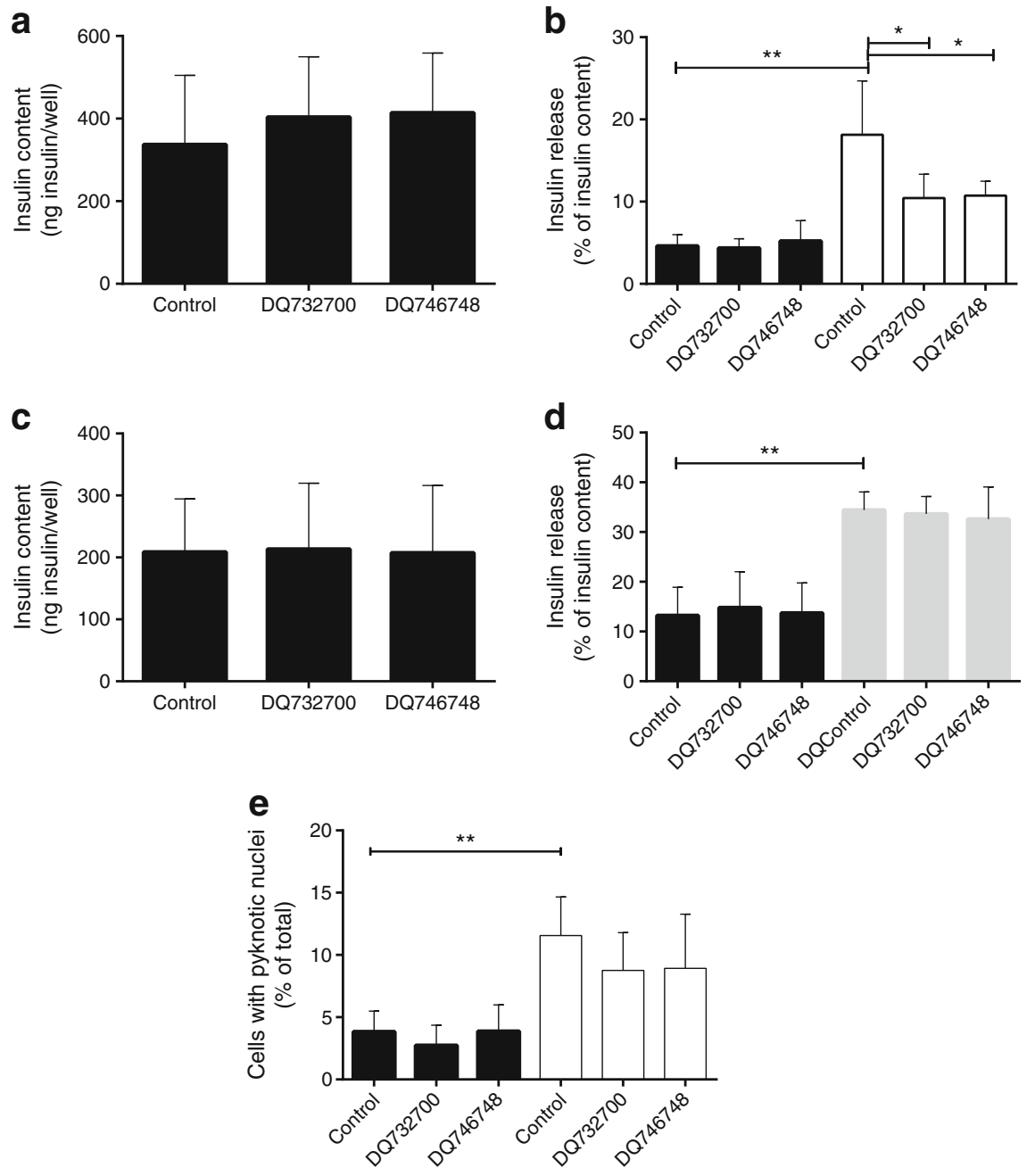

proliferation and to inhibit apoptosis in human cervical cancer tissues by downregulating the $\mathrm{p} 14 \mathrm{ARF} / \mathrm{p} 53$ pathway [47]. A decrease in level of these Piwil genes has also been found to be associated with tumour progression and reduced survival of individuals with renal carcinoma [43]. Thus, the role of Piwil genes may vary according to the cellular context. In our study, we observed that downregulation of Piwil2 and Piwil4 mRNAs in beta cells had a protective effect against cytokine-induced cell death and no significant impact on proliferation. Further investigations will be needed to precisely delineate the signalling pathways through which Piwil2 and Piwil4 affect the survival of beta cells.

In this study, we identified several piRNAs that are differentially expressed in the islets of diabetic GK rats, a Wistar substrain obtained by selective breeding of a colony displaying high blood glucose levels. The genetic determinants responsible for the development of diabetes in GK rats are not yet fully established. Thus, the observed changes in piRNA expression may either be due to genetic differences between the GK and Wistar substrains or be the consequence of chronic hyperglycaemia. To investigate the potential role of these piRNAs in beta cell dysfunction and the development of type 2 diabetes, we selected two piRNAs that are upregulated in the islets of GK rats and overexpressed them in the islets of control Wistar rats. Interestingly, this resulted in a selective defect in glucose-induced insulin secretion, providing initial evidence for a contribution of piRNA deregulation to the diabetic phenotype of GK rats. The overexpression of these two piRNAs did not affect cell survival, indicating that the defect in insulin secretion did not result from a toxic effect of these small RNAs. The mechanism through which DQ732700 and DQ746748 affect insulin secretion remains to be determined. As KCl-induced insulin secretion is not impaired, the overexpression of these two piRNAs is unlikely to perturb the expression of general components of the exocytotic machinery.

Our findings would rather suggest that the overexpression of DQ732700 and DQ746748 interferes with the generation of metabolic factors coupling glucose sensing to insulin release. Alternatively, the piRNAs may affect granular recruitment, a process that is dependent on metabolic factors [48, 49]. piRNAs have been suggested to control gene expression via mechanisms analogous to those of microRNAs [14]. 
Computational prediction of the potential targets of these two piRNAs highlighted an enrichment in genes involved in insulin secretion, insulin action or carbohydrate digestion. Future studies need to experimentally validate these targets and assess whether their silencing can indeed contribute to the effect of the piRNAs.

The unexpected discovery of the existence of thousands of non-coding transcripts with regulatory properties opens new perspectives in the understanding of the mechanisms that govern the activities of mammalian cells. Our data provide initial evidence for an involvement of piRNAs in the control of beta cell functions under both physiological and pathological conditions. These findings add an additional layer of control to the regulation of gene expression in insulin-secreting cells. A better understanding of the role and the mode of action of piRNAs in beta cells will help to elucidate the molecular events driving the acquisition of a mature beta cell phenotype and the causes of beta cell dysfunction in diabetes conditions. This knowledge will be instrumental in engineering beta cell surrogates to replace insulin-secreting cells and in promoting the development of new therapeutic strategies for the treatment of type 2 diabetes.

Data availability Data have been deposited in Gene Expression Omnibus repository under the accession number GSE93792. Data can be accessed via the following link:

https://www.ncbi.nlm.nih.gov/geo/query/acc.cgi?token= ojklueugdzehpkv\&acc=GSE93792

Funding This work was supported by the European Foundation for the Study of Diabetes (RR), Swiss National Foundation grants 310030146138 and 310030-169480 (RR), the Fondation Francophone pour la Recherche sur le Diabète sponsored by the Fédération Française des Diabétiques, AstraZeneca, Eli Lilly, Merck Sharp \& Dohme, Novo Nordisk and Sanofi (RR) and the Swedish Research Council (LE).

Duality of interest The authors declare that there is no duality of interest associated with this manuscript.

Contribution statement IH, CJ, IGM, CG and JS generated and analysed the data. CJ, IGM, CG and JS critically revised the manuscript and approved its final version. LE contributed to interpreting the data, critically revised the manuscript and approved its final version. RR designed the experiments and interpreted the data. IH and RR wrote the manuscript and approved its final version. RR is the guarantor of this work.

\section{References}

1. Girard A, Sachidanandam R, Hannon GJ, Carmell MA (2006) A germline-specific class of small RNAs binds mammalian Piwi proteins. Nature 442:199-202

2. Watanabe T, Takeda A, Tsukiyama T et al (2006) Identification and characterization of two novel classes of small RNAs in the mouse germline: retrotransposon-derived siRNAs in oocytes and germline small RNAs in testes. Genes Dev 20:1732-1743
3. Aravin A, Gaidatzis D, Pfeffer S et al (2006) A novel class of small RNAs bind to MILI protein in mouse testes. Nature 442:203-207

4. Grivna ST, Beyret E, Wang Z, Lin H (2006) A novel class of small RNAs in mouse spermatogenic cells. Genes Dev 20:1709-1714

5. Siomi MC, Sato K, Pezic D, Aravin AA (2011) PIWI-interacting small RNAs: the vanguard of genome defence. Nat Rev Mol Cell Biol 12:246-258

6. Hirakata S, Siomi MC (2016) piRNA biogenesis in the germline: from transcription of piRNA genomic sources to piRNA maturation. Biochim Biophys Acta 1859:82-92

7. Brennecke J, Aravin AA, Stark A et al (2007) Discrete small RNAgenerating loci as master regulators of transposon activity in Drosophila. Cell 128:1089-1103

8. Luteijn MJ, Ketting RF (2013) PIWI-interacting RNAs: from generation to transgenerational epigenetics. Nat Rev Genet 14:523-534

9. Le Thomas A, Rogers AK, Webster A et al (2013) Piwi induces piRNA-guided transcriptional silencing and establishment of a repressive chromatin state. Genes Dev 27:390-399

10. Yan Z, Hu HY, Jiang X et al (2011) Widespread expression of piRNA-like molecules in somatic tissues. Nucleic Acids Res 39: 6596-6607

11. Ross RJ, Weiner MM, Lin H (2014) PIWI proteins and PIWIinteracting RNAs in the soma. Nature 505:353-359

12. Lim RS, Kai T (2015) A piece of the pi(e): the diverse roles of animal piRNAs and their PIWI partners. Semin Cell Dev Biol 4748:17-31

13. Itou D, Shiromoto Y, Yukiho SY et al (2015) Induction of DNA methylation by artificial piRNA production in male germ cells. Curr Biol 25:901-906

14. Gou LT, Dai P, Yang JH et al (2014) Pachytene piRNAs instruct massive mRNA elimination during late spermiogenesis. Cell Res 24:680-700

15. Zhang P, Kang JY, Gou LT et al (2015) MIWI and piRNA-mediated cleavage of messenger RNAs in mouse testes. Cell Res 25:193-207

16. Esposito T, Magliocca S, Formicola D, Gianfrancesco F (2011) piR_015520 belongs to Piwi-associated RNAs regulates expression of the human melatonin receptor 1A gene. PLoS One 6:e22727

17. Huang XA, Yin H, Sweeney S, Raha D, Snyder M, Lin H (2013) A major epigenetic programming mechanism guided by piRNAs. Dev Cell 24:502-516

18. Mani SR, Megosh H, Lin H (2014) PIWI proteins are essential for early Drosophila embryogenesis. Dev Biol 385:340-349

19. Rajasethupathy P, Antonov I, Sheridan R et al (2012) A role for neuronal piRNAs in the epigenetic control of memory-related synaptic plasticity. Cell 149:693-707

20. Rizzo F, Hashim A, Marchese G et al (2014) Timed regulation of Pelement-induced wimpy testis-interacting RNA expression during rat liver regeneration. Hepatology 60:798-806

21. Assumpcao CB, Calcagno DQ, Araujo TM et al (2015) The role of piRNA and its potential clinical implications in cancer. Epigenomics 7:975-984

22. Lim SL, Ricciardelli C, Oehler MK, Tan IM, Russell D, Grutzner F (2014) Overexpression of piRNA pathway genes in epithelial ovarian cancer. PLoS One 9:e99687

23. Cheng J, Guo JM, Xiao BX et al (2011) piRNA, the new noncoding RNA, is aberrantly expressed in human cancer cells. Clin Chim Acta 412:1621-1625

24. Lee JH, Schutte D, Wulf G et al (2006) Stem-cell protein Piwil2 is widely expressed in tumors and inhibits apoptosis through activation of Stat3/Bcl-XL pathway. Hum Mol Genet 15:201-211

25. Janic A, Mendizabal L, Llamazares S, Rossell D, Gonzalez C (2010) Ectopic expression of germline genes drives malignant brain tumor growth in Drosophila. Science 330:1824-1827

26. Yan $\mathrm{H}, \mathrm{Wu} \mathrm{QL}$, Sun CY et al (2015) piRNA-823 contributes to tumorigenesis by regulating de novo DNA methylation and angiogenesis in multiple myeloma. Leukemia 29:196-206 
27. Jeffery N, Harries LW (2016) Beta-cell differentiation status in type 2 diabetes. Diabetes Obes Metab 18:1167-1175

28. Eliasson L, Esguerra JL (2014) Role of non-coding RNAs in pancreatic beta-cell development and physiology. Acta Physiol (Oxford) 211:273-284

29. Guay C, Regazzi R (2015) Role of islet microRNAs in diabetes: which model for which question? Diabetologia 58:456-463

30. Knoll M, Lodish HF, Sun L (2015) Long non-coding RNAs as regulators of the endocrine system. Nat Rev Endocrinol 11:151160

31. Esguerra JL, Bolmeson C, Cilio CM, Eliasson L (2011) Differential glucose-regulation of microRNAs in pancreatic islets of non-obese type 2 diabetes model Goto-Kakizaki rat. PLoS One 6:e18613

32. Gotoh M, Maki T, Satomi S et al (1987) Reproducible high yield of rat islets by stationary in vitro digestion following pancreatic ductal or portal venous collagenase injection. Transplantation 43:725-730

33. Kohler M, Dare E, Ali MY et al (2012) One-step purification of functional human and rat pancreatic alpha cells. Integr Biol (Camb) 4:209-219

34. Jacovetti C, Matkovich SJ, Rodriguez-Trejo A, Guay C, Regazzi R (2015) Postnatal beta-cell maturation is associated with isletspecific microRNA changes induced by nutrient shifts at weaning. Nat Commun 6:8084

35. Kertesz M, Iovino N, Unnerstall U, Gaul U, Segal E (2007) The role of site accessibility in microRNA target recognition. Nat Genet 39:1278-1284

36. Durinck S, Spellman PT, Birney E, Huber W (2009) Mapping identifiers for the integration of genomic datasets with the R/Bioconductor package biomaRt. Nat Protoc 4:1184-1191

37. Nishimasu H, Ishizu H, Saito K et al (2012) Structure and function of zucchini endoribonuclease in piRNA biogenesis. Nature 491: 284-287

38. Siomi MC, Mannen T, Siomi H (2010) How does the royal family of Tudor rule the PIWI-interacting RNA pathway? Genes Dev 24: 636-646
39. Portha B, Lacraz G, Kergoat M et al (2009) The GK rat beta-cell: a prototype for the diseased human beta-cell in type 2 diabetes? Mol Cell Endocrinol 297:73-85

40. Cox DN, Chao A, Baker J, Chang L, Qiao D, Lin H (1998) A novel class of evolutionarily conserved genes defined by piwi are essential for stem cell self-renewal. Genes Dev 12:3715-3727

41. Watanabe T, Cheng EC, Zhong M, Lin H (2015) Retrotransposons and pseudogenes regulate mRNAs and lncRNAs via the piRNA pathway in the germline. Genome Res 25:368-380

42. Krishnan P, Ghosh S, Graham K, Mackey JR, Kovalchuk O, Damaraju S (2016) Piwi-interacting RNAs and PIWI genes as novel prognostic markers for breast cancer. Oncotarget 7:37944-37956

43. Iliev R, Stanik M, Fedorko M et al (2016) Decreased expression levels of PIWIL1, PIWIL2, and PIWIL4 are associated with worse survival in renal cell carcinoma patients. Onco Targets Ther 9:217222

44. Suzuki R, Honda S, Kirino Y (2012) PIWI expression and function in cancer. Front Genet 3:204

45. Enfield KS, Martinez VD, Marshall EA et al. (2016) Deregulation of small non-coding RNAs at the DLK1-DIO3 imprinted locus predicts lung cancer patient outcome. Oncotarget

46. Lu Y, Zhang K, Li C et al (2012) Piwil2 suppresses $\mathrm{p} 53$ by inducing phosphorylation of signal transducer and activator of transcription 3 in tumor cells. PLoS One 7:e30999

47. Su C, Ren ZJ, Wang F, Liu M, Li X, Tang H (2012) PIWIL4 regulates cervical cancer cell line growth and is involved in down-regulating the expression of p14ARF and p53. FEBS Lett 586:1356-1362

48. Ivarsson R, Obermuller S, Rutter GA, Galvanovskis J, Renstrom E (2004) Temperature-sensitive random insulin granule diffusion is a prerequisite for recruiting granules for release. Traffic 5:750-762

49. Varadi A, Ainscow EK, Allan VJ, Rutter GA (2002) Involvement of conventional kinesin in glucose-stimulated secretory granule movements and exocytosis in clonal pancreatic beta-cells. J Cell Sci 115:4177-4189 